Klehe, U. \& Van Hooft, E.A.J. (in press).

Handbook of job loss and job search. Oxford University Press, Oxford

Chapter 13: Understanding the Motivational Dynamics among Unemployed Individuals:

Refreshing Insights from the Self-Determination Theory Perspective

\author{
Maarten Vansteenkiste \\ University of Gent, Belgium \\ Anja Van den Broeck \\ Univeristy College Brussels, Belgium \\ KU Leuven, Belgium
}

Corresponding author:

Maarten Vansteenkiste

H. Dunantlaan 2

9000 Gent

E-mail: Maarten.Vansteenkiste@ugent.be

$0032 / 9 / 2646413$ 


\begin{abstract}
Although the role of motivation has been emphasized in the field of unemployment and job search, the motivational dynamics underlying unemployed individuals' behaviour have not received yet the attention they deserve. In this chapter, we present a motivational perspective grounded in Self-Determination Theory (SDT), a macro-theory on human motivation in social context. We discuss basic principles of SDT and formulate seven propositions that have direct relevance for the fields of unemployment and job search. When discussing these propositions, we elucidate similarities and differences between SDT and various frameworks in the unemployment and job search literature and cover the available empirical evidence in the realm of SDT in these fields. Given that the literatures on job search and unemployment have been developed fairly independently, we conclude that SDT represents a promising theory to bridge these two fields, and may equally provide useful guidelines for practitioners in the field.
\end{abstract}

Key terms: Job search, unemployment, self-determination theory, motivation, work values, need satisfaction 


\section{Understanding the Motivational Dynamics among Unemployed Individuals: Refreshing Insights from the Self-Determination Theory Perspective}

In the context of unemployment, political leaders often have their mouth full of the fact that unemployed people need to be "activated". The term activation basically implies that we need to find ways to motivate unemployed individuals in general and at in risk groups (e.g., longterm unemployed; elderly unemployed) in particular. Specifically, we need to stimulate those unemployed who would not be sufficiently active and motivated by themselves to search for employment. Although it is clear that (at least some) unemployed individuals need to be activated or motivated, the way how to do so varies widely across political parties and ideologies. Depending on one's political affiliation, an activation policy can take the form of being highly prescriptive and controlling or can be rather supportive and take the unemployed person's rhythm, situation, and personal choices into consideration.

For instance, at least in Belgium, a "do ut des" credo seems to be increasingly adopted by different political parties, suggesting that in return for their unemployment benefits unemployed people must search for a job and have to accept any job that is offered to them, particularly after multiple refused job offers or a certain amount of time. Consistent with this idea and in light of the worldwide financial crisis of the last couple of years, consensus in Europe is growing that the unemployment benefits of the passive unemployed should be gradually withdrawn. Such a measure would subject non-active unemployed individuals to financial pressures and eventually help to speed up their reemployment process, thereby reducing the percentage of long-term unemployed individuals. Yet, research does not provide evidence for such reasoning as financial hardship fails to predict job search behaviour, (re)employment, let alone quality of (re)employment. 
In addition to the plead for a gradual withdrawal of employment benefits, some political parties also suggest investing in the creation of additional jobs such that unemployed individuals would be offered a broader array of jobs. This would increase the chance they will accept a job that fits their interests and preferences. Although governmental policies represent a mix of prescriptive, sanctioning, supportive and facilitative measures, this cocktail can vary widely from one country to another, with resulting implications for the unemployed.

Indeed, the efficacy of these various policy measures at the macro-level can be understood from a psychological and, more specifically, motivational perspective. Unemployed individuals find themselves embedded within a broader societal context which impacts their individual motivation because unemployed individuals interact with unemployment counsellors and employers who are equally affected by the policy installed by their local and national governments (Deci \& Ryan, 2012). To fully understand how individual unemployed individuals are affected, we argue that it is critical to consider the amount and type of job search motivation fostered by different societal policies, employers, and individual unemployment counselors.

The importance of studying motivational dynamics was already highlighted by Marie Jahoda (1981) more than three decades ago. She noted that 'motivation .... is obviously relevant for understanding people at work or without it' (p. 184). Although motivational dynamics have received quite some attention by scholars in the unemployment literature (Creed, King, Hood, \& McKenzie, 2009; Kanfer, Wanberg, \& Kantrowitz, 2001), the attempts to study motivational processes were not systematically informed by more general social-motivation theories (Feather, 1990; Jahoda, 1981). In line with Feather's call to directly ground unemployment research in such mid-range or grand psychological theories, we present the Self-Determination Theory (SDT) view (Deci \& Ryan, 2000; Ryan \& Deci, 2000a) on the motivational dynamics involved in unemployment. SDT is a macro-theory of human motivation, emotion, and personality that has 
been under development for nearly forty years following the seminal work of Edward Deci and Richard Ryan. In its current status, SDT compromises five different mini-theories (Vansteenkiste, Niemiec, \& Soenens, 2010), which each yield relevance for the domain of unemployment. Rather than presenting these five mini-theories in an exhaustive and theory-driven fashion, we chose to organize the chapter around four larger sections, that is, (1) 'The energetic basis of motivation: Basic psychological need satisfaction'; (2) 'Why of behavior'; (3) 'What of behavior'; (4) 'Facilitating motivation: The role of contextual need-support'. Each of these sections begins with a discussion of the basic features of the SDT framework. The provided theoretical basis then allows us to formulate seven propositions that yield direct relevance for the fields of unemployment and job search. When discussing these propositions, we indicate similarities and differences between SDT and various other frameworks within the literature on unemployment and job search, including Jahoda's model (Jahoda, 1981, 1982), Fyer's agency model (Fryer, 1986), expectancy-valence models (Feather, 1990), and current self-regulation models (Wanberg, Zhu, Kanfer, \& Zhang, in press), we cover the limited available research on SDT in the domains of unemployment and job search, and we provide a number of future research directions.

\section{THE ENERGETIC BASIS OF MOTIVATION:}

\section{PSYCHOLOGICAL NEED SATISFACTION}

One of the central assumptions of SDT is that people are inherently proactive, that is, they have the potential to act on and master both the internal (i.e., drives and emotions) and the external (i.e., environmental) forces they encounter, rather than being passively controlled by those forces. Further, SDT assumes that through their activity humans steadily move towards increasing levels of psychological growth and integration. Yet, this pro-activity and growth does not take place automatically but needs to be facilitated by the social environment in the form of 
the support of the basic psychological needs for autonomy, competence, and relatedness (Deci \& Ryan, 2000; Deci \& Vansteenkiste, 2004; Ryan \& Deci, 2000a).

Psychological needs have been defined as "innate psychological nutriments that are essential for ongoing psychological growth, integrity, and well-being" (p. 229). Because of their inborn character, the psychological needs are considered part of human nature (Deci, 1992) and their satisfaction is said to be fundamental for individuals' wellness and psychological health. Specifically, just as plants need sunshine and water to flower, according to SDT, human beings need to experience the satisfaction of these needs to be optimally motivated and to feel well, both psychologically and physically. Yet, SDT also recognizes that people have vulnerabilities, such as those for being aggressive, defensive or passive, and maintains that the active frustration and blocking of these very same psychological needs awakens these vulnerabilities (Ryan \& Deci, 2000b; Vansteenkiste \& Ryan, 2013).

Within SDT, three inborn needs are identified, that is, the need for autonomy, competence, and relatedness. Autonomy concerns the desire to experience personal ownership over one's actions, thoughts, and emotions and to engage in an activity with a sense of volition and psychological freedom. When satisfied, unemployed persons likely feel that they are searching for a job out of volition and that they can be themselves, without feeling the obligation to hide or suppress feelings like resentment, fear, or sadness. Competence concerns the desire to feel effective in what one does and in mastering new skills in the process. When satisfied, unemployed persons will feel that they are making progress towards their desired goals (e.g., writing an application letter). Finally, relatedness refers to the desire to develop satisfying and deeply anchored relationships. Unemployed people who feel understood by their partner or an unemployment counselor in coping with the frustration that goes along with being unemployed experience a sense of relatedness and connectedness. 
In line with SDT, several studies have demonstrated that need satisfaction relates positively to indices of well-being (e.g., life satisfaction, vitality) and negatively to indices of illbeing (e.g., depression). Need satisfaction plays a role at different levels of generality, with differences in need satisfaction between persons, groups, and nations accounting for well-being differences between individuals (e.g., Wilson, Rogers, Rogers, \& Wild, 2006), groups (e.g., Vansteenkiste, Lens, Soenens, \& Luyckx, 2006; Meyer, Enström, Harstveit, Bowles, \& Beevers, 2007), and nations (e.g., Sheldon, Cheng, \& Hilpert, 2011), respectively. Need satisfaction has been found to play a critical role at the within-person level as well, with daily fluctuations in autonomy, competence, and relatedness being uniquely associated with daily differences wellbeing (e.g., Ryan, Bernstein, \& Brown, 2010). Finally, need satisfaction has been found to predict optimal functioning in domains as diverse as schooling, exercise, work, and psychotherapy (see Deci \& Ryan, 2000; Vansteenkiste et al., 2010 for general overviews) and in both individualistic and collectivistic-oriented cultures (e.g., Chen, Vansteenkiste, Beyers, Soenens, \& Van Petegem, 2013). Herein, we suggest that psychological need frustration can help to account for the observed well-being decrements of unemployed individuals, which leads to the formulation of our first proposition.

Proposition One: The frustration of the basic psychological needs can account for the negative impact of unemployment on well-being.

Dozens of studies examined whether unemployed individuals experience less psychological and physical health and more ill-being relative to employed individuals. Two recent meta-analytical reviews (McKee-Ryan, Song, Wanberg, \& Kinicki, 2005; Paul \& Moser, 2009; Wanberg, 2012) provided a summary of these studies, showing that unemployed individuals report lower psychological health (e.g., lower self-worth and more worries, fear, and depression) and physical health (e.g., more heart trouble and hypertension) than their employed 
counterparts. These differences were more pronounced among men, blue collar workers, longterm unemployed and school leavers. Moreover, the association between employment status and psychological health is not only a concurrent one, but a change from employment to unemployment has been found to yield an increase in distress. Although less psychologically adjusted employees might have a greater likelihood of becoming unemployed, research mostly supports the notion that that becoming unemployed causes a change in well-being (Creed \& Bartrum, 2006).

Several models in the organizational/industrial literature, such as Jahoda's latent deprivation model (Jahoda, 1982) and Warr's vitamin model (Warr, 1987), help to account for these findings. Jahoda (1982) argued that, besides the manifest function of providing financial benefits, employment serves several important latent functions, that is, time structure, social contact, collective purpose, social identity or status, and regular activity. Because unemployed individuals are denied these experiential categories, they display well-being deficits. In a similar vein, Warr (1987) suggests that unemployed are relatively deprived from environmental aspects such as opportunities to develop their skills and social support. According to Warr, these aspects serve as vitamins improving - up to a certain degree - individuals' well-being. Although Fryer and Payne (1986) recognize the importance of these benefits, they emphasized in their agency restriction model more strongly the manifest function of employment. The decrease or loss of income places a financial burden on unemployed individuals, which is highly distressing. In line with these arguments, the deprivation of these latent and manifest functions have been found to account for observed well-being decrements of unemployed individuals, with especially financial strain being a strong predictor of unemployed individuals' experiences of distress (e.g., Creed \& Klisch, 2005; Paul \& Batinic, 2010).

Although appealing, these accounts are rather descriptive in nature as the provided 
explanation is not tied to or guided by a formal theory. Such more global, social-psychological theories have received increasing attention in the field of unemployment and job search. One such a promising framework is SDT. As noted, from a SDT-perspective, for humans to flourish, their innate basic psychological needs have to get satisfied. We maintain that, on average, unemployed individuals might be more prone to psychological need frustration. For instance, they often need to handle financial and social pressures during their job search and their job search increasingly becomes a daunting duty, such that their need for autonomy gets frustrated. Their daily activities may feel like a "chain of obligations" and "musts". Moreover, unemployed individuals might also start to doubt their capacities. Especially in the case of prolonged unemployment duration which often goes together with an increasing number of rejections, their need for competence might get actively frustrated (Vansteenkiste, De Witte, \& Lens, 2006). Finally, their social network might gradually erode till a point they feel socially isolated or excluded from society, which frustrates their relatedness need (Underlid, 1996).

Notably, meaningful links can be drawn between the three psychological needs identified within SDT and the manifest and latent functions identified by Jahoda, Warr, and Fryer and Payne. For instance, the deprivation of social contact reduces opportunities for relatedness satisfaction and may even elicit feelings of loneliness. The lack of time structure and regular activity in one's life might preclude one's opportunities for the experience of competence, because ill-structured days might leave one with the feeling that one is unable to achieve any outcome. Further, as far as occupying a job is central to one's identity, one might have the feeling that unemployment alienates oneself from one's preferences and ideals, thereby negatively impacting on one's need for autonomy. Finally, financial strain might result in unwanted pressures, worries, and stress that frustrate one's need for autonomy. Future research may jointly assess these latent and manifest functions (e.g., Muller, Creed, Waters, \& Machin, 2005; Paul \& 
Batinic, 2010) and the satisfaction of the basic psychological needs among unemployed individuals as to examine their associations and their explanatory role in the association between unemployment status and well-being.

\section{"WHY" OF BEHAVIOR}

According to SDT, the satisfaction of the basic psychological needs for autonomy, competence, and relatedness provides the energetic basis for optimal forms of motivation. The more the psychological needs during one's job search get satisfied, the more unemployed persons develop an autonomous, relative to controlled, job search motivation. Autonomous and controlled motivation reflect different categories or reasons for engaging in a particular behavior (e.g., job searching). In the context of unemployment, the type of job search motivation is said to contribute to various outcomes such as unemployment experience, job search intensity and job search quality, employability, as well as speed and quality of reemployment.

As can be noticed in Figure 1, autonomous and controlled motivation include different motivational subtypes. The prototype of autonomous motivation is intrinsic motivation (Ryan \& Deci, 2000a). In the case of intrinsic motivation, people engage in an activity for the inherent pleasure and satisfaction it provides (Deci, 1975). For instance, unemployed persons may derive a sense of enjoyment from exploring the job market and trying to find a job that meets their interests. Curiosity forms the impetus for intrinsically motivated behavior and at least some people, perhaps especially school leavers, are simply very curious to find out which jobs are available on the job market. Because individuals are spontaneously following their interests during such explorative behavior, intrinsic motivation is said to represent the hallmark of autonomous or volitional behavior.

Although some unemployed might experience searching for a job as enjoyable, for many unemployed individuals searching for a job is a rather unpleasant duty that requires considerable 
effort from their side (Van Hooft, Wanberg, \& van Hoye, 2013). Also, some unemployed individuals have lost their interest in searching over time due to repeated rejections (Vansteenkiste, et al., 2006). In spite of the lack of enjoyment (i.e., intrinsic motivation) of searching as such, unemployed individuals can still be autonomous in their searching given they have accepted the reason for doing so as their own. This process has been labelled the process of ‘internalisation' and has been intensively studied within SDT. Conceptually, internalisation refers to incorporating the value or reason for engaging in a particular behaviour (e.g., job searching) into one's own value system, so that people experience a sense of personal ownership over their behaviour (Deci \& Ryan, 2000). Because this process can be variably successful, different regulatory subtypes have been distinguished, with some of them being rather controlled and others being rather autonomous in nature.

Controlled regulation entails engaging in an activity out of a sense of pressure and two subtypes have been discerned (see Figure 1). The first form of controlled regulation involves the execution of behaviours to comply with external demands (i.e., external regulation). Such external pressures can be tangible or rather social in nature: one can engage in the activity to obtain a contingent material reward or to avoid a tangible threatening punishment or one can engage in the activity to gain social appreciation or to avoid criticism. For instance, school leavers who search to avoid further nagging of their parents display external regulation, just as long-term unemployed looking for a job because they have difficulties to make both ends meet. This external form of motivation has received quite some attention in past unemployment research as the role of financial pressures in the job search process and well-being of unemployed individuals has been studied (e.g., McKee-Ryan et al., 2005).

Notably, the pressure to search does not necessarily reside in external forces as people can also pressure oneself into the activity, for instance, by linking their behavioural regulation to 
threats of self-imposed guilt, shame, or a loss of self-worth. This second type of controlled regulation is labelled introjected regulation. Although the behavioural regulation has been taken in this case and introjected regulation thus constitutes internal regulation, the reason for performing the activity has not been fully accepted as one's own, yet (i.e., partial internalisation). As result, the behavioural engagement is experienced as internally conflicted, tense, and pressured. The unemployed person who search because they feel ashamed of being jobless or because they believe they are taking advantage of society display introjected regulation just as the school leavers who are searching because they are afraid of coming across as lazy. Likely, individuals with a strong Protestant work ethic (Furnham, 1987) might display a mix of this internally pressuring type of job search regulation in combination with more fully internalized types of job search regulation.

Parallel to the bifurcation of controlled motivation, different subtypes of autonomous motivation have been proposed. When unemployed people have internalised the reason for engaging in job searching, they are said to display identified regulation, that is, they concur with the personal importance of job searching. In the case of identification, unemployed people search for a job because they perceive searching and finding work as personally meaningful for a selfselected goal, like developing their talents or personality. The highest level of internalisation is achieved when one not only concurs with the value of searching as such but also perceives fit between the value attached to searching for a job and other personally held values and ideals. This has been labelled integrated regulation. When integrated, the values and ideals of unemployed individuals form a coherent and harmonious whole, such that their job searching emanates from themselves. For instance, the unemployed searching for a job because they believe that work allows them to offer their children a better education would display integrated 
regulation. Similarly, employed job seekers often search for a different employment to better coordinate their different roles, like being a caring mother and an engaged employee.

Autonomous and controlled motivated behavior is intentional in nature, that is, the behaviour is oriented towards achieving a particular outcome. Amotivation, in contrast, is characterized by a lack of intention. When amotivated, people do not or rather passively engage in the required behavior; they are said to go "through the motions". Amotivaton may result from the feeling that one is incapable to engage in a particular behaviour (efficacy expectation), that the required activity does not bring the desired outcome (outcome expectation), or because one devalues the activity all together (Ryan, Lynch, Vansteenkiste, \& Deci, 2011). For instance, an unemployed person who does not know how to start his job search displays amotivation, just as the unemployed who beliefs that he will not be hired, even when he would perform well in a job interview.

The distinction between autonomous and controlled motivation and amotivation has been proven useful to predict one's performance, persistence, and well-being in a wide variety of life domains, including sport, education, work, and psychotherapy (Deci \& Ryan, 2000; Vansteenkiste, Niemiec et al., 2010). Yet, it is only recently that these motivational dynamics were studied in the job search and unemployment domain, which leads to the formulation of our second proposition.

Proposition Two: The type of job search motivation matters for unemployed people's job search intensity and unemployment experience.

In one of the first studies on job search motivation, Vansteenkiste, Lens, Dewitte, De Witte, and Deci (2004) developed the self-regulation - job search questionnaire, which taps into unemployed individuals' autonomous and controlled reasons for job searching. In two large samples of long-term unemployed individuals, the various SDT-based job search motives could 
be factor-analytically distinguished and the retained factors correlated in meaningful ways with other constructs. For instance, both autonomous and controlled motivation correlated positively with job commitment (Warr et al., 1981), which is in line with the idea that they both reflect a certain degree of motivation (convergent validity). Further, controlled motivation correlated positively with financial concerns, while autonomous motivation related positively to job search optimism and the expectancy to find a job and amotivation correlated negatively with job search optimism and the expectancy to find a job. These findings highlight that the different types of behaviour regulation associate with different constructs (divergent validity).

Next, the pattern of external outcomes associated with both types of motivation was markedly different: While autonomous motivation was positively related to job search behaviour over the past three months, controlled motivation and amotivation were unrelated to job search behavior. In addition to this behavioural outcome, a number of general well-being outcomes (i.e., GHQ, life satisfaction, self-actualization) and unemployed individuals' positive and negative experiences of their unemployment situation were assessed. Negative experiences concern unemployed individuals' feeling of social isolation, worthlessness and meaningfulness (De Witte \& Wets, 1996). Positive experiences tap the extent to which unemployed individuals feel more relaxed since they get jobless and are able to enjoy their spare time. Across the two studies, autonomous motivation related positively to self-actualization, was unrelated to life satisfaction and general health and associated negatively with the positive experience of one's unemployment. It seems plausible that autonomously motivated unemployed, who likely have a sincere interest in getting a job, have difficulty to enjoy their free time; yet, through their searching, they feel that they are actualizing their potential and don't feel devalued as a person. In contrast, controlled motivation and amotivation related positively to negative experiences of one's unemployment and negatively to general well-being. Thus, the more individuals report 
controlled motivated or amotivation, the more they experience their unemployment status as negative and the more they pay a well-being price for it.

In a recent study, Koen, Klehe, and Van Vianen (in press) studied the role of motivation in a sample of long-term unemployed individuals who were following a mandatory reemployment course. Results showed that unemployed displaying relative more autonomous than controlled reasons for searching reported an increase in job searching and employability after the termination of the reemployment course. Apparently, the relatively more autonomous motivated unemployed were capable of extracting greater benefits from the mandatory course.

These motivational dynamics were are also found to be relevant among school-leavers who undertake their first steps on the job market. Specifically, in a study among $12^{\text {th }}$ and $13^{\text {th }}$ grade school leavers (Soenens \& Vansteenkiste, 2005), relative autonomous motivation for searching was found to relate positively to the intention to search for a job in the future as well as to school leavers' exploration and commitment of their vocational identity. Exploration and commitment represent two critical identity dimensions in Marcia’s classic identity status paradigm (Marcia, 1966; Kroger \& Marcia, 2011). Exploration of one’s vocational identity refers to exploring different options on the job market, while commitment refers to making a particular job choice which one fully endorses and feels certain about. School leavers' type of job search motivation was found to be implicated in school leavers' identity formation (LaGuardia, 2009; Soenens \& Vansteenkiste, 2011): autonomously motivated school leavers have more energy available to explore different job openings and are more capable of committing themselves to a particular option. They might commit themselves more easily because they are in better contact with their preferences, interests and values, such that they have a clearer view of what the job they really value and want. We would predict that such sincere interest and personal valuation of a particular job would also be sensed by interviewers during a job application such that 
autonomous motivated candidates may be more quickly hired. This hypothesis deserves being tested in future research.

A short-term longitudinal study by Grant, Nurmohamed, Ashford and Dekas (2011) provides some preliminary evidence for this hypothesis. Specifically, in a sample of job applicants, they found that taking initiative during the job search process related to a greater number of job offers in case the job applicants scored high on autonomous and low on controlled job search motivation. The fact that only the combined presence of high autonomous and low controlled motivation yielded a long-term benefit suggests that applicants' job search motivation should be of very high quality to get translated in positive outcomes over the longer term.

Apart from studies among job seekers, the relevance of the distinction between autonomous and controlled motivation has recently been studied among part-time workers (Halvari, Vansteenkiste, Brorby, \& Karlsen, 2013). Specifically, Norwegian part-time working nurses, who are generally encouraged to search for a full-time job, indicated their reasons for searching for a full-time employment. Replicating the findings among job seekers, autonomous job search motivation related positively to the self-reported search for a full-time position. Further, controlled motivation was unrelated to job search but also negatively related to the positive experience of one's spare time as a part-time worker.

To summarize, the aforementioned studies indicate that autonomous and controlled motivation represent qualitative different types of motivation, with autonomous motivation yielding more desirable correlates compared to controlled motivation. From an applied perspective this implies that it is not only critical that unemployed individuals get activated and motivated, but also that they display the "right" type of motivation. These findings are perhaps counterintuitive, because unemployment counselors, unemployed people and scholars frequently assume that unemployed individuals' level of motivation is of critical importance, regardless of 
the type of motivation. Specifically, more strongly motivated jobless people are assumed to more quickly find a (new) job, presumably because they put greater effort into their searching. Yet, based on SDT, we maintain it is important to move beyond merely considering unemployed individuals' intensity of motivation and to additionally consider the sort or type of motivation they display. In line with these claims, Vansteenkiste, Lens, De Witte, and Feather (2005) found that, autonomous and controlled motivation accounted for incremental variance in unemployed individuals' job search, unemployment experience, and well-being after controlling for unemployed people's amount of job search motivation, operationalised in terms of the expectancy to find a job and employment commitment as detailed in expectancy-valence theory (Feather, 1990, 1992; Feather \& Davenport, 1981),

In our view, the research that is available to date indicates that studying unemployed individuals' quality of motivation represents a fruitful avenue for future research. Specifically, longitudinal studies would need to examine whether type of job search motivation (i.e., autonomous or controlled) relates to (a) quality of job search (Van Hooft, Wanberg, \& Van Hoye, 2013), (b) attributions for being rejected during an application interview (Weiner, 1985), (c) speed and (d) quality of (re)employment. We elaborate on these issues below.

Although many scholars (e.g., Kanfer et al., 2001; Vinokur \& Schul, 2002; Wanberg, Hough, \& Song, 2002; Van Hoye, this volume) emphasized the importance of unemployed people's job search quality, in the majority of studies the assessment of job search behaviour has been limited to its intensity. High quality job search has been defined "performing one's job search activities in such a way that those meet/exceed the expectations of the demanding parties of the labour market (e.g., selection organization, recruiters, assessors, hiring managers, counsellors)" (Van Hooft, et al., 2013, p. 7). We would expect that although controlled motivation might engender some behavioural engagement, especially autonomous motivation 
would relate to high quality behaviour. For instance, autonomously motivated individuals might submit more carefully crafted job applications, might perceive an application interview as a challenge rather than a threat and might come across as more enthusiastic and authentically interested during a job application interview. Consistent with such predictions, previous research in the academic domain indicated that whereas controlled motivation engenders superficial learning, autonomous motivation relates to deep-level learning (e.g., Benware \& Deci, 1984; Vansteenkiste, Simons, Lens, Soenens, \& Matos, 2005), predicts a lowered threat response to a stressful event (Hodgins, et al., 2010) and relates to higher engagement as rated by external observers (e.g., Aelterman et al., 2012; Reeve, Jang, Carrell, Jeon, \& Barch, 2004). In this context, it would also be interesting to examine relations between different motivations and the active (i.e., focused and exploratory) and passive (i.e., haphazard) job search strategies outlined by Crossley and Highouse (2005). Autonomous job seekers are most likely to be focused in their job search, perhaps after a period of broader exploration of different options (see Soenens \& Vansteenkiste, 2005). Because of the lack of a clear view of their vocational identity, amotivated individuals might engage in the trial and error approach characteristic of the haphazard strategy. Quality of job search motivation might also predict one's reaction towards failure during the job search process. Because controlled motivated individuals' ego and self-worth is more contingent upon the outcome of job search, they might engage in more self-handicapping prior to the application interview to protect their ego (e.g., Hodgins, Yacko, \& Gottlieb, 2006). They might also experience a rejection as a stronger blow to their self-worth compared to autonomously oriented individuals. In an attempt to protect their self-worth, they may react more defensively, thereby providing external attributions for their failure (e.g., the attitude of the interviewer). Autonomously oriented unemployed individuals might be more open for feedback (Hodgins \& Knee, 2002), thereby trying to understand why they are not accepted for the job and 
perceiving the feedback as a source of information for taking new steps in their job search and personal development.

Regarding the speed of (re)employment, the available cross-sectional research suggests autonomous motivation will relate to a quicker (re)employment. Yet, unemployed individuals who are subjected to financial pressures might also find employment, albeit the type of accepted job might be different. One potential explanatory mechanism in this process forms job flexibility (Reilly, 1998), that is the strictness of the demands of jobless people regarding their future jobs (De Witte, 1993). Because controlled motivated individuals may be more ready to sacrifice the content of their job to gain quick employment, they may apply for a diversity of jobs such that they get quickly engaged. In contrast, because autonomous motivated unemployed people are committed to a particular vocational identity, they might be more picky and selective in their job search and only apply for jobs that really fit their interests. This more focused job search likely results in better quality (re)employment (Crossley \& Highhouse, 2005), as indexed by higher job satisfaction, engagement and lower absenteeism rates (Koen, Klehe, \& Van Viaenen, 2010). The focused search of autonomously oriented individuals would allow them to occupy high quality jobs with greater opportunities for basic psychological need satisfaction (Van den Broeck, Vansteenkiste, De Witte, Soenens, \& Lens, 2010).

Future longitudinal work may also examine how people's motivational regulations change as a function of their unemployment duration. Because unemployment duration may impact on unemployed people's experiences of need satisfaction, their motivational regulation may change. For instance, because continued unemployment often goes hand in hand with repetitious rejections and, hence, competence-thwarting experiences, unemployed individuals may lose their curiosity to spontaneously explore the job market and instead become apathic (i.e., amotivated; see Vansteenkiste, et al., 2006). Also, the searching might be experienced as increasingly 
autonomy-thwarting because the searching is experienced as a daunting duty. Said differently, due to increasing experiences of need thwarting associated with longer unemployment duration, unemployed people's reasons for searching will become increasingly alien to their sense of self. This leads us to elaborate in the next section on the meaning of the notion of self as defined in SDT and modern self-regulation models.

Proposition Three: The notion of 'self' carries a different meaning in modern selfregulation models compared to SDT

Since the millennium, self-regulation models have received increasing attention within the field of unemployment research (Kanfer, Wanberg, \& Kantrowitz, 2001; Wanberg, Zhu et al., 2012). Because the term self-regulation surfaces in the SDT-vocabulary, it is critical to discuss whether the SDT's view on self-regulation resembles the notion of self-regulation as used in the job search literature. We argue that both notions of self-regulation are not equivalent, because the notion of 'self' carries a different meaning in the SDT and job search literature, which yields important theoretical and practical implications.

Within self-regulation models in the job search literature, job seeking is conceived as a goal-setting process, that is, as "a purposive, volitional pattern of action that begins with the identification and commitment to pursuing an employment goal" (Kanfer et al., 2001, p. 838). Self-regulated job seekers are said to be capable to effectively cycle through different phases of the job search process (Van Hooft et al., 2013). Self-regulatory job seekers are, for example, able to establish a desired job seeking goal to which they are committed (e.g., writing two application letters a week). They carefully plan their job search activities, for instance, by forming implementation intentions (Gollwitzer, 1990) specifying when, where, and how they will realize their plans. During their actual job search, they engage in a variety of processes to monitor their goal progress. When encountering obstacles (e.g., rejection during job application interview), 
they are capable of handling the resulting disruptive emotions. Self-regulatory job seekers also are persistent and are able to modify their strategies as to increase the probability of achieving their goals. Apart from specifying these different stages, scholars in the job search literature focused on three key self-regulatory strategies, that is, (a) work commitment, which refers to the desire to close the gap between one's current unemployment and being employed, (b) emotion control, which involves the use of self-regulatory strategies to cope with negative emotions such as shame, guilt, and anger, (c) motivation control, which involves the engagement in a variety of strategies (e.g., self-talk; visualizing positive outcomes) to facilitate persistence during the job search process (e.g., Creed et al., 2009).

Although this brief discussion does not justify the richness of these self-regulation models (see Latham et al., this volume for a more extensive presentation), we want to address three key points when discussing this self-regulation view in relation to SDT. First, by describing the selfregulatory stages and by identifying the self-regulatory strategies of the job search process, these self-regulation models primarily indicate how job searchers can embark and successfully engage in the job search process. Put briefly, these phases and strategies denote the "how" of job search. Yet, the cycling through these phases and the engagement in these strategies requires energy, and, hence, a motivational basis. Current self-regulation models in the job search literature, perhaps due to their rather descriptive focus, stay more silent about the factors that supplement this energy (Ryan \& Deci, 1999). By considering the job search process as a goal-related endeavor, it remains unclear where these goals come from in the first place. SDT can fill this theoretical gap as its organismic approach provides the basis to gain insight in the process of goal-selection and, hence, the "why" of job search behavior. Further, the interface between the social environment and the living organism endowed with psychological needs fuels individuals' goals with 
psychological meaning and provides the necessary energy for continued goal pursuit (Ryan \& Deci, 1999).

Of course, the "why" of behavior will relate to the "how" of job search. Yet, not all types of job search motivation are equally predictive of the engagement in self-regulatory strategies. As noted above, autonomous but not controlled motivation was found to be associated positively with job commitment (Soenens \& Vansteenkiste, 2005). Further, both types of motivation are differentially related to a variety of emotional coping strategies, with autonomous motivation being positively related to the positive reinterpretation of one's unemployment situation and controlled motivation being related to mental disengagement, denial, and drug use. Finally, as for the engagement in motivational control strategies, autonomously motivated job searchers were found to engage in a variety of pro-active job search strategies, such as planning and the suppression of competing activities (Vansteenkiste, 2010).

Second, the engagement in goal-related activities (e.g., planning) can by itself be motivated by very different reasons. For instance, an unemployed person could choose to make up a plan for the upcoming week (e.g., writing an application letter) because she really believes that making a plan is helpful in achieving her desired goals. Alternatively, she might also feel pressured to make up a plan, for instance because an employment counselor insisted upon doing so. From a SDT-perspective, however, the reasons underlying these self-regulatory strategies will determine their effectiveness. If the planning is controlled, rather than autonomously motivated, it is less likely that job seekers will stick to their planning instead procrastinating their job search (Senecal \& Guay, 2000; Van Hooft et al., 2005). In line with these claims, experimental work by Koestner, Lekes, Powers, and Chicone (2002) demonstrated that the formulation of implementation intentions (i.e., a self-regulatory strategy recommended in the job search 
literature; Van Hooft et al., 2013) resulted in more goal progress when participants had autonomous rather than controlled reasons for pursuing these goals.

A third issue concerns the meaning attributed to the term 'self'. As noted by Ryan and Deci (1999), in many contemporary self-regulation models, 'self is synonymous with person, such that all of one's psychic make-up is self' (p. 195). The notion of self then refers to the fact that an unemployed person is internally, rather than externally, regulating his job search behavior. SDT converges with contemporary self-regulation models on the idea that an unemployed person can better search out of internal than external reasons. Yet, different types of internal regulation are distinguished: some of them being more coercive, internally conflicted and, hence, alien to the growth-oriented self (i.e., introjected regulation as part of controlled regulation) and others being more volitional, authentic and, hence, congruent with the growth-oriented self (i.e., autonomous regulation). As such, not all job search strategies considered to be self-regulated from a self-regulation perspective represent true or volitional self-regulation from the SDT viewpoint! In this respect, we argue that we need to be careful in the use of the term 'volitional', which was used by Kanfer et al. (2001, p. 838) to characterize job seeking as a self-regulatory process. This is because not all unemployed individuals engage in self-regulatory job search strategies, as advocated in self-regulation models, volitionally or willingly. This is not just a terminological issue, as different types of internal regulation have been found to yield different correlates, with internally conflicted, relative to internally harmonious, types of regulation yielding an emotional cost (e.g., Assor, Vansteenkiste, \& Kaplan, 2009; Koestner \& Pelletier, 2002).

At the practical level, this analysis suggests that unemployment counselors may not want to foster any type of internal regulation but rather promote autonomous types of internal regulation. A concrete example might help to illustrate this point. Many politicians and 
unemployment counselors alike emphasize that unemployed individuals need to learn to take responsibility for their situation and the activation of unemployed individuals involves highlighting this responsibility. When considered from the process of internalization, the notion of responsibility has an ambiguous meaning as it can be indicative of one's autonomous commitment to search for a job or it may be indicative of an internal demand pushing one to take up one's responsibility (see Miller, Das, \& Chakravarthy, 2011). In daily practice, at least some unemployment counselors point towards the responsibility of unemployed individuals in a guiltinducing way, for instance, by conveying the message that non-active job searchers are lazy or are taking advantage of society. When facing such guilt-inducing language, unemployed people might feel devalued and, for this reason, take up their responsibility for internally pressuring reasons. They might have the impression that unemployment counselors project their own work ethic on them, thereby bypassing their reasons for not searching. From the SDT-perspective, it is critical to be open for unemployed people's reasons for not searching, as the lack of engagement in job search behavior can represent a self-endorsed choice or a sign of oppositional defiance, as highlighted in proposition four.

Proposition Four: Not searching can represent a self-endorsed choice or an indication of oppositional defiance.

Most motivation theories restrict themselves to asking the question why individuals engage or fail to engage in a target activity. Yet, given the constant flux of people's activities (Atkinson \& Birch, 1970), people's motivation for a target activity likely also depends on their reasons for engaging in alternative activities. This implies that people's non-engagement in the target activity is not necessarily function of their amotivation, but could also represent a fully endorsed choice because they give priority to an alternative activity. For instance, an unemployed person might decide not to search for a job because he gives priority to taking care of his sick 
mother or to follow a vocational training. Alternatively, individuals may have the impression they are not allowed to engage in the target activity because they feel pressured or seduced to take part in such alternative activities. For instance, an unemployed person might not search for because his wife wants him to take care of the children or because he feels like a bad father if he would not take sufficiently care of his children.

Consistent with this idea, Vansteenkiste et al. (2004) examined whether the autonomouscontrolled motivation distinction can be applied to both the engagement and non-engagement in job search behavior. In addition to being asked why they were searching for a job, long-term unemployed individuals were asked why they were not searching, thereby tapping into their autonomous and controlled motives not-to-search. Interestingly, the motives not to search predicted additional variance in participants' unemployment experiences and general well-being above and beyond the "classic" SDT-motives to search (i.e., autonomous motivation, controlled motivation, and amotivation). Specifically, controlled motivation not-to-search yielded a unique positive relation with a negative experience of one's unemployment. Autonomous motivation not-to-search related positively to enjoying the benefits of being unemployed (i.e., positive unemployment experience) and overall well-being, while being negatively related to feeling devalued or socially isolated due to one's unemployment (i.e., negative unemployment experience). Thus, whereas autonomous motivation to search was- as noted above - unrelated to general well-being, the often observed positive correlates for autonomous motivation were found for the construct of autonomous non-engagement. Presumably, unemployment allows autonomous non-engaged individuals to achieve their ideals and values, while autonomously job seeking individuals have not yet achieved their personally valued goal of being employed. Consistent with these findings, Halvari et al. (2013) found autonomous motivation not-to-search 
for full-time employment to relate positively to positive experiences of one's part-time position, while being negatively related to job search intensity.

The idea that the autonomous-controlled distinction can be symmetrically applied to individuals' engagement and non-engagement is fairly novel. Thus, a lot of work still can be done in this area. One intriguing possibility is that controlled non-engagement can take the form of oppositional defiance, in which an unemployed person aims to differentiate himself from external forces by seeking independence (Deci \& Ryan, 1985; Vansteenkiste, Soenens, Van Petegem, \& Duriez, 2013). For instance, an unemployed person who would react against social norms and legislations by rejecting the authority figure instantiating the norms would display oppositional defiance. Oppositional defiant behavior is controlled in nature, because one is rebelling against pushing external (authority) figures.

Although trait-differences in oppositional defiant behavior would arise as a function of being exposed to need-thwarting experiences during childhood (Vansteenkiste \& Ryan, 2013), such defiance can also be easily activated by a partner or unemployment counselor in a single conversation (i.e., at the state level). Indeed, because some unemployed people perceive searching versus not searching for a job as their personal business, they are very sensitive for any signals pushing them into a particular direction. As a result, straightforwardly activating those unemployed individuals to seek employment, especially in a controlling and forceful way, will likely elicit oppositional defiance because they have the feeling that these activation attempts represent a threat to their autonomy, a point also central to psychological reactance theory (Brehm, 1966). Not only threats to one's autonomy, but also to one's relatedness and competence may activate oppositional defiance. When unemployment counselors or family members are highly critical or cynical about a person's capacity to find a job, unemployed people will feel rejected (relatedness frustration) and worthless (competence frustration). Such intense 
experiences of need thwarting may initially cause anger and opposition and, when experienced repeatedly as is the case for long-term unemployed individuals, result in apathy and amotivation. In future work, it would be interesting to examine the interactions between unemployment counselors and unemployed individuals in terms of how need-supportive versus need-thwarting a counselor acts and whether the unemployed person displays signs of oppositional defiance. Previous research grounded in motivational interviewing (Miller \& Rollnick, 2002) among alcohol addicts indicated that patients' resistance towards change and long-term abstinence varies as a function of the confronting versus empathic approach of the counselor (e.g., Miller \& Baca, 1983; Miller, Taylor, \& West, 1980).

Another possibility for future research is to conduct diary studies (e.g., Wanberg, Zu, \& Van Hooft, 2010) in which participants report on their motives for searching or not searching, need satisfaction, well-being and job search behavior. It could be examined how day-specific autonomous and controlled reasons for searching and not searching relate to each other over time. Although not framed from a SDT-perspective, a diary study by Wanberg, et al. (2010) indicated that there is considerable variation in unemployed people's job search efforts. Unemployed people also differed in terms of reasons for not searching, which nicely map onto the categories distinguished within SDT. For instance, some of commonly used reasons for not searching on a given day were 'had family obligations', 'wanted to do other things', and 'discouragement', which nicely correspond to the categories of 'controlled non-engagement', 'autonomous nonengagement', and 'amotivation', respectively. Future work could also examine how these motives for searching and not searching relate to unemployed people's daily or weekly functioning, both in terms of searching efforts, made progress, and relational and personal wellbeing. Such an intra-individual approach seems particularly well-suited method to study 
unemployed people's motivation (and lack thereof) from a more dynamic perspective (Brown \& Ryan, 2006).

Finally, it could be examined which processes explain the positive association between an autonomous motivation not-to-search and well-being. Because autonomous non-seekers choose to not search and give priority to other meaningful activities, they might not experience as much deprivation in the latent benefits of employment. Instead, they might experience their unemployment time as well structured and purposeful (Bond \& Feather, 1988), built up a satisfying network of contacts and be engaged in a variety of activities, which, in turn, may contribute to the satisfaction of their basic psychological needs. Given the observed well-being correlates of autonomous motivation not-to-search, we suggest in proposition five that motivational dynamics might play a moderating role in the unemployment-ill-being association.

Proposition Five: Quality of motivation may play a moderating role in the unemploymentill-being association

Although meta-analytical reviews indicate that becoming unemployment yields on average a deterioration in well-being (McKee-Ryan, et al., 2005; Paul \& Moser, 2009), considerable variation around this average effect exists, such that being unemployed might not be health-impairing for all unemployed individuals. This raises the question which variables may play a moderating role.

Various moderators have been studied in the unemployment literature, including age, gender, length of unemployment, family unemployment, local levels of unemployment, attributions of causes of job loss, personality variables and values (Creed \& Bartrum, 2006). From the SDT-perspective, one potential moderator involves unemployed individuals' autonomous and controlled motives for searching and not searching for a job. To further the understanding of the impact of unemployment, person-centered analyses might be useful. Such 
analyses allow one to identify different groups of unemployed individuals characterized by a particular motivational profile, that is, a combination of reasons for engaging and not engaging in job search. Such motivational profiles have been studied in the educational (e.g., Hayenga \& Corpus, 2010; Vansteenkiste, Sierens et al., 2009), physical education (Haerens, Kirk, Cardon, De Bourdeauduij, \& Vansteenkiste, 2010), sport (Gillet, Vallerand, \& Rosnet, 2009), and work domain (Van den Broeck, Lens, De Witte, \& Van Coillie, 2013). Whereas some of these retained groups were found to score relatively high on both autonomous and controlled motivation, others scored relatively low on both dimensions and still other groups displayed a combination of high autonomous and low controlled motivation or vice versa. Interestingly, these groups differed substantially in their degree of self-regulation (e.g., time management; effort regulation) and well-being (e.g., engagement; stress), with more autonomously motivated groups displaying the most optimal outcomes.

Similar person-centered analyses could be performed among unemployed individuals to discover subgroups of unemployed individuals and examine mean-level differences in well-being and the use of self-regulatory search strategies. These retained motivational profiles could then be compared with the motivational profiles extracted from a matched employment group. It is well possible that employed individuals who belong to a poor quality motivation group (i.e., a group characterized by high on controlled and low on autonomous work motivation) display an equal or even lower level of well-being compared to unemployed individuals in the good quality motivation group (i.e., high on autonomous and low on controlled job search motivation). These analyses could further be refined by adding unemployed individuals' autonomous and controlled motivation not-to-search as additional dimensions in the person-centered analyses. Given that the dimension of autonomous motivation not-to-search positively relates to unemployed people's well-being (Vansteenkiste et al., 2004), a group of unemployed individuals characterized by high 
autonomous motivation not-to-search may not suffer from being unemployed. Finally, it could be examined whether differences in well-being across the motivational subgroups could be accounted for by differences in need satisfaction during unemployment.

\section{"WHAT" OF BEHAVIOR}

Besides the reasons or behavioural regulation of unemployed individuals to (not) search for a job (i.e., the 'why'), SDT also considers the type of goals or values unemployed individuals strive for (i.e., the 'what'; Deci \& Ryan, 2000; Kasser \& Ryan, 1996; Vansteenkiste, Soenens, \& Duriez, 2008). For most unemployed individuals finding a job is their most important goal. However, the specific goals unemployed individuals want to achieve via their work may vary considerably. Some unemployed individuals value employment in general and a specific job in particular because it allows them to meaningfully contribute to society or to develop their skills. Others value jobs that are well respected or that allow them to become materially successful. From the perspective of more quantitative oriented theories, such as expectancy values theory and goal setting theory, the specific goals unemployed individuals aim to achieve via their new job is of little importance as long as unemployed people highly value employment per se or are highly focused on achieving the goal of reemployment (Ryan, Sheldon, Kasser, \& Deci, 1996). SDT, in contrast, maintains that the type of work goals unemployed individuals pursue during job search may yield important repercussions, as different types of goals relate differently to unemployed individuals' job flexibility, job choice, and, hence, also the experienced need satisfaction and well-being at their future job.

Specifically, SDT differentiates global intrinsic aspirations, such as contributing to the community, building social bonds, and developing one's skills, from global extrinsic aspirations, such as accumulating accumulate wealth, acquiring fame and social recognition, and having power and influence over others (Kasser \& Ryan, 1996). When applied to the field of 
unemployment and work, an intrinsically oriented individual would value opportunities for skilldevelopment and formation at the job, while an extrinsically oriented individual would value a high status job where he is, for example, seen as leader or high potential. Intrinsic and extrinsic goal-contents have been found to yield different well-being correlates (e.g., Kasser \& Ryan, 1996) because they allow for a differential degree of need satisfaction. While intrinsic goal pursuit would be conducive to basic need satisfaction (e.g., Sebire, Standage, \& Vansteenkiste, 2009), extrinsic goal pursuit would be unrelated or would even interfere with the satisfaction of one’s basic psychological needs (e.g., Verstuyf, Vansteenkiste, \& Soenens, 2012). When pursuing such outward oriented goals, one's ego and self-worth is more at stake and one is less likely to get fully immersed in the activity at hand (Schmuck, Kasser, \& Ryan, 2000; Vansteenkiste, Simons, Lens, Soenens, Matos, \& Lacante, 2004). Moreover, extrinsic goal oriented individuals are more likely to adopt a competitive worldview that justifies the discrimination of threatening out-groups (Duriez, Soenens, et al., 2007) and to make use of others to get ahead in life (Sheldon, Sheldon, \& Osbaldiston, 2000), behaviors that reduce one's opportunities for basic need satisfaction. The research on individuals' work-related goals is still scarce, but suggests that these different goal-contents may yield a number of different correlates, both among unemployed and employed individuals, which is outlined in proposition six.

Proposition Six: Intrinsic and extrinsic work goals yield different correlates among unemployed individuals

To shed light on the different dynamics involved in the pursuit of intrinsic and extrinsic goals, Van den Broeck, Vansteenkiste, Lens and De Witte (2010) related these different goalcontents to unemployed individuals' flexibility to accept a job that deviate from their ideal job (De Witte, 1993; Vandoorne, De Witte, \& Hooge, 2000). After controlling for various background characteristics, perceived financial hardship and general employment value, they 
found that intrinsic goals related positively to both training flexibility (i.e., the willingness to attend extra courses to find employment) and pay flexibility (i.e., the willingness to accept job that pays less well than what could be expected based on one's level of education or work experience). In contrast, the pursuit of extrinsic goals related negatively to these types of flexibility. This pattern of relations suggests that extrinsic goal oriented individuals adopt a less flexible attitude towards the labour market. Most importantly, they seem to reject these types of flexibility that may yield beneficial effects in the long term as they choose jobs that may offer reduced opportunities for basic psychological need satisfaction. By being strict about one's pay level, extrinsically oriented individuals might end up choosing jobs that are well-paid but yet are of a rather poor quality, for example, in terms of the job resources these jobs offer (Warr, 1987; Bakker \& Demerouti, 2007). By being unwilling to participate in job training, they are less likely to develop their skills and competencies. Such a job training, which intrinsically oriented individuals are more likely to engage in, might, however, open up new job possibilities, which likely lead to high-quality and more enduring employment characterized by higher levels of experienced psychological need satisfaction.

Consistent with this reasoning, Van den Broeck (2010) found in a sample of graduating university students that intrinsic and extrinsic work goals related differently to individuals' engagement and burn-out assessed two years later. Intrinsic work goals related positively to engagement and negatively to burn-out, while extrinsic work goals related negatively to engagement. These prospective associations could be accounted for by the fact that intrinsic work goals related positively to job resources, while extrinsic work goals yielded a negative relation. These findings provide preliminary evidence that unemployed people's goal-contents relates to their future job well-being, although it remains to be studied which mechanisms can account for this association. These different goal-contents may - via the above mentioned accompanying 
types of flexibility - relate to the choice of jobs that differ in terms of their afforded job characteristics (self-selection mechanism). During the search for a new job, unemployed individuals with different goal contents likely pay attention to different aspects of job vacancies, with intrinsic goal oriented unemployed individuals being more attracted to vacancies highlighting job content, societal relevance, and social relations, while extrinsic oriented unemployed individuals being attracted to vacancies highlighting high wages and prestigious functions. Apart from this self-selection mechanism, it is also possible that individuals with different goal-profiles evoke different job characteristics through a process of job crafting (evocative mechanism) or interpret and react to the available job characteristics differently (reactive mechanism; see Van den Broeck, Van Ruysseveldt, Smulders, \& De Witte, 2010).

Regardless of the mechanisms at work, previous work has demonstrated that the pursuit of intrinsic, relative to extrinsic, work goals associated positively with job satisfaction and work engagement and negatively with burnout and intention to turn-over (Vansteenkiste, Neyrinck et al., 2007). This relation could be accounted for basic psychological need satisfaction at work. Along similar lines, Promislo, Deckop, Giacalone, and Jurkiewicz (2010) showed that the negative effects of a materialistic orientation are not limited to the work place but may radiate to family life, as a materialistic orientation related to more work-family conflict. Indeed, extrinsic oriented individuals might work long hours to achieve their extrinsic ambitions, which takes time away to engage family or leisure time activities. Overall then, the current findings suggest that to the extent that organisations attract unemployed individuals with an extrinsic, rather than an intrinsic, goal profile, their employees are more likely to display reduced job well-being and might also more easily quit the organisation.

At this point, some might argue that to the extent that extrinsic goals are central to the culture of the organisation, organisations might actually benefit from hiring extrinsic oriented 
unemployed individuals. This position is maintained within the match-perspective (e.g., Sagiv \& Schwartz, 2000) and the person-environment fit paradigm (Kristof-Brown, Zimmerman, \& Johnson, 2005). Indeed, it would be in the advantage of both the organisation and the employees themselves that the goal-profile of employees matches the goal-profile encouraged within the organisation culture. Said differently, if social prestige, competition, and money are central aspects of an organisation's culture, it is likely that a highly competitive and materialistic oriented unemployed individual would thrive in such an organisation. From the SDT-perspective, the critical question is whether such an extrinsic-extrinsic match actually creates opportunities for basic psychological need satisfaction. This might be rather unlikely, as previous work has shown that extrinsically oriented business students don't display elevated well-being although extrinsic goals are more likely present in their study environment (Kasser \& Ahuvia, 2002; Vansteenkiste, Duriez, Simons, \& Soenens, 2006).

\section{FACILITATING MOTIVATION: THE ROLE OF CONTEXTUAL NEED SUPPORT}

It is assumed that autonomous motivation and intrinsic goal pursuit can be either promoted or undermined depending on whether the environment nourishes or blocks satisfaction of basic psychological needs for autonomy, competence, and relatedness (Deci\& Ryan, 2000; Ryan, 1995). Parallel to the three needs, SDT distinguishes autonomy-supportive versus controlling, well-structured versus chaotic, and involved versus distant social environments. To date, most of work within SDT has focused on the support of autonomy, but recent research witnesses an increasing interest in the topics of structure (e.g., Jang, Reeve, \& Deci, 2010) and involvement (e.g., Grolnick \& Ryan, 1989). The concept of need-support allows one to evaluate the (de)motivating impact of (a) individual persons (e.g., partner, family, unemployment counselors) who interact on a frequent basis with unemployed people and (b) the measures taken at the societal level. 
Autonomy-supportive individuals dealing with unemployed people use inviting language and allow for participation and dialogue. They provide choices and give a meaningful rationale for a request. Perhaps, the core feature of autonomy support involves working from the unemployed person's frame of reference. This can be achieved by being curious about the unemployed person's view such that he feels fully understood and validated. Rather than displaying an authentic interest in the other's viewpoint, a controlling style involves approaching unemployed individuals from one's own or stereotyped (e.g., "unemployment is the result of one's own fault"; "unemployed individuals take advantage of society") standards, which are then used to judge the unemployed and to push them into action. Such coercion can be achieved by using overt (e.g., "I count on the fact that you write two application letters this week") or more subtle (e.g., "You get a monthly unemployment benefit, thus society expects something in return from you're your side") controlling language or by threatening the unemployed with external consequences (e.g., "If you keep on just hanging around here and stay unemployed, our marriage will fall apart"). A controlling approach then often takes the form of contingent regard (Roth, Assor, Niemiec, Ryan, \& Deci, 2009), which involves buttressing one’s appreciation and disappointment depending on people's effort-expenditure and accomplishments.

Structure involves the setting of clear expectations and the provision of desired help, guidance and information, and, if needed, a detailed step-by-step plan, such that obstacles to achieve (re)employment are eliminated. Structuring socializing agents are stimulating and encouraging and provide competence-supportive feedback. As such, they guide the goal setting and goal achievement process of the unemployed individual. It is critical that structure is introduced in an autonomy-supportive way (Jang, Reeve, \& Deci, 2009; Sierens, Vansteenkiste, Goossens, Soenens, \& Dochy, 2009). All too often though, socializing agents (e.g., counselors, partners, parents) provide information that is not desired and, as a result, comes across as 
redundant or even irritating. Although the provision of such information is intended to be helpful, it is not perceived as such by the person being socialized because the information does not build a sense of competence. Instead it only highlights what a person already knows. Finally, involvement is expressed through the display of a concern with the unemployed person's situation such that the unemployed person feels fully understood.

Although the benefits of socializing agents' need support has been demonstrated in dozens of studies in domains outside the unemployment literature, including the sport, work, education, and health care domain (Deci \& Ryan, 2000), there is a paucity of work on need support in the domain of job search and unemployment, leading to proposition seven.

Proposition 7: Autonomous motives to search and not-to-search can be facilitated through the provision of need-Support

In one study among school-leavers, Soenens and Vansteenkiste (2005) examined the role of parental and teacher autonomy-support in the prediction of school-leavers' relative autonomous motives for searching for a job in the near future. It was found that whereas maternal autonomy-support was unrelated, both teacher and paternal autonomy-support yielded a unique positive association with school-leavers' relative autonomous motives for searching. Importantly, the mandatory nature of reemployment courses does not by definition elicit a controlled job search motivation in the unemployed, as far as the necessity and personal usefulness of the mandatory course is well explained to the unemployed. In line with this, Koen, Klehe, and Van Viaenen (in press) showed that unemployed people who perceived a mandatory course as personally meaningful had better endorsed the value of searching for a job, with increasing levels of internalization in part accounting for a positive change in employability. Yet, if such courses were not perceived as personally meaningful, the unemployed likely felt the course was yet another daunting duty from which they could extract little if any benefits. 
Clearly, more research is needed in this area. For instance, it needs to be demonstrated that counselor autonomy support, structure and involvement relate to the unemployed persons' experience of need satisfaction which, in turn, predicts their motivational regulations and their emotional regulation strategies. One interesting avenue involves studying the interactions between counselors and unemployed individuals in terms of the provided need support at the micro-level (for instance, through observations). This would help us to get a better insight in what exactly need-supportive counselors are doing and saying during these conversations (see Reeve, 2006 for an example in education) and to shed light on the interview techniques they use (see Markland, Ryan, Tobin, \& Rollnick, 2006; Vansteenkiste, Williams, \& Resnicow, 2012). For instance, the language used by counselors might be quite different, with controlling counselors using more "should"-language and autonomy-supportive counselors being more inviting (e.g., Vansteenkiste, Simons, Lens, Sheldon, \& Deci, 2004).

Although scholars and practitioners might agree that it is critical to support unemployed people's autonomous motives for search, the question how to deal with unemployed individuals who choose not to search might be more controversial. This issue contains at least two different layers, that is, the question (a) whether you need to motivate and activate unemployed individuals who are autonomously not searching for a job and, if so, (b) how you can motivate them. The answer to the first question will be informed by one's world view, political affiliation, empirical and ethical considerations. As noted, empirically, autonomous motivation not-to-search has been found to yield a positive relation to well-being (Vansteenkiste, Simons, Lens, Sheldon, et al., 2004), presumably because those unemployed individuals find themselves in their personal desired situation, which allows them to get their basic needs met. Also, within SDT (Ryan, Lynch, Vansteenkiste, \& Deci, 2011), it has been argued that the support of autonomy is an end in itself, a goal that can be justified on ethical grounds. At times, this also implies supporting the 
individual to not engage in a particular activity (e.g., searching). Indeed, autonomy-support does not represent a motivational technique to trick unemployed individuals into searching for a job. If unemployment counselors start a dialogue with the unemployed with the explicit aim of activating them, they might come across as manipulative. Thus, they would not be exercising autonomy support but some form of "pseudo-autonomy support".

This does not imply that unemployment counsellors need to adopt a permissive, laissezfaire attitude, as if they cannot clarify their expectations or point out the consequences of nonsearching to the unemployed person. Yet, what is critical is the timing of and the way how these issues get discussed. Need-thwarting unemployment counsellors directly confront unemployed persons with the consequences of their non-searching behaviour, for instance by suggesting that finding employment is their societal duty and that not searching will be sanctioned (e.g., removal of unemployment benefits). At least some unemployed people are very much aware of the consequences of their non-searching and, hence, the information provided by counsellors will not be experienced as very helpful. Instead, because of its redundant character, the information might cause irritation and prompt a defensive reaction. To avoid such oppositional defiant reactions, need-supportive counsellors would express interest and be curious about why the unemployed person did not search for a job over the past weeks. Through such interest taking non-searching unemployed persons would be validated rather than being judged for not living up to the counsellor's and societal expectations.

Having addressed the reasons for not searching, autonomy-supportive counsellors would choose the right moment to friendly ask whether the unemployed person has reasons to search for a job. If it turns out that the reasons for not searching outweigh the reasons for searching, needsupportive unemployment counsellors would respect unemployed persons' viewpoint, yet point out that there might be consequences associated with not searching (e.g., removal of 
unemployment benefits). Rather than highlighting the evaluative value of these consequences by presenting them as threatening sanctions ("We will need to sanction you, if you do not do X or Y"), counsellor would adopt a need-supportive style, thereby emphasizing the informational value of these consequences. Need-supportive counsellors would, for instance, be curious to hear whether unemployed persons views the consequences associated with not searching as unfair and illegitimate and they would offer a meaningful rationale and relevant information for why such a system is installed by the government. If unemployed persons are already aware of these reasons, they would be asked to self-generate those reasons as to avoid that redundant information would be provided.

Thus, in the end the pros or not searching but also searching would be discussed by needsupportive counsellors, yet, need-supportive counsellors would pay careful attention to the order in which and the way how this would be done. In general, a need-supportive unemployment counsellors would voice unemployed persons' reasons for not searching rather than rejecting them and pushing the person to start searching for a job. The latter approach would create tension and conflict and would be experienced as need-thwarting by both the unemployed person and the counselor, such that the unemployed person would fail to endorse the decision to start searching for a job.

At a broader level then, need-supportive counselling does not imply that one stays silent about societal measures to foster reemployment, including the gradual removal of unemployment benefits or the necessity to participate in mandatory training programs. This would be typical for a laissez-faire approach. There are likely good reasons why governments decided to gradually remove unemployment benefits or to organize mandatory training programs. Need-supportive counsellors would discuss these reasons and would highlight the informational value of these 
societal measures, while at the same time minimizing the controlling aspect of them (Dec i\& Ryan, 1985).

\section{Conclusion}

Rather surprisingly, the literatures on the well-being effects of unemployment and unemployed people's job search behavior have been developed fairly independently. One reason for this is perhaps that an overarching theory that allows one to study both phenomena simultaneously is currently missing. SDT might help to bridge the gap between both literatures, as SDT specifies the explanatory mechanisms (basic need satisfaction) and moderators (quality of motivation in terms of behavioral regulations and goals) of the unemployment-well-being link. Further, the type of motives underlying search behavior relate to unemployed people's intensity of searching, employability, and their (re)employment success. A lot of work still needs to be done in this area, but the few SDT-based studies on unemployment and job search and the wealth of empirical evidence in other life domains indicate that truly motivating unemployed people involves more than putting them under pressure such that they get activated. For activation policies to be effective in the long term, that is, to promote high quality (re)employment, policy makers, counselors, and family need to nurture unemployed people's basic psychological needs for autonomy, competence, and relatedness. 


\section{Practical Guidelines}

- Counselors do well to move beyond considering unemployed people's level of motivation to search by also taking into account the type of reasons (autonomous or controlled) underlying unemployed people's search behavior.

- A lack of motivation to search not only stems from discouragement after repetitive rejections, but could also represent a more deliberate and well-reflected choice or an attempt to defy pressuring authority figures.

- Putting pressure on people to search a job may be effective in the short-term, but yield considerable collateral damage in the long terms, as indexed by lowered well-being and poor quality reemployment.

- To foster autonomous search motivation, counselors do well to adopt a counseling style supportive of employed people's psychological needs for autonomy, competence, and relatedness.

- Autonomy support manifests through the provision of desired choice, the offering of a meaningful rationale, the unconditional acceptance of unemployed people's functioning, the use of inviting rather than controlling language, and the display of a sincere curiosity in unemployed people's reasons for both searching and not searching. 


\section{References}

Aelterman, N., Vansteenkiste, M., Haerens, L., Vandenberghe, L., Demeyer, J., \& Van Keer, H. (2012). Pupils' objectively measured physical activity levels and engagement as a function of between-class and between-pupil differences in motivation towards physical education: A self-determination theory approach. Journal of Sport \& Exercise Psychology, 34, 457-480.

Assor, A., Vansteenkiste, M., \& Kaplan, A. (2009). Identified versus introjected-approach and introjected-avoidance motivations in school and in sports: The limited benefits of selfworth strivings. Journal of Educational Psychology, 101, 482-497.

Atkinson, J. W., \& Birch, D. (1970). The dynamics of action. New York: Wiley.

Bakker, A. B., \& Demerouti, E. (2007). The job demands-resources model: State of the art. Journal of Managerial Psychology, 22, 309-328.

Benware, C., \& Deci, E. L. (1984). Quality of learning with an active versus passive motivational set. American Educational Research Journal, 21, 755-765.

Bond, M. J., \& Feather, N. T. (1988). Some correlates of structure and purpose in the use of time. Journal of Personality and Social Psychology, 55, 321-329.

Brehm, J. W. (1966). Theory of psychological reactance. San Diego, CA: Academic Press.

Brown, K. W., \& Ryan, R. M. (2006). Multilevel modeling of motivation: A Self-determination theory analysis of basic psychological needs. In A. D. Ong \& M. van Dulmen (Eds.), Oxford handbook of methods in positive psychology (pp. 1158-1183). New York, NY: Oxford University Press.

Chen, B., Vansteenkiste, M., Beyers, W., Soenens, B., \& Van Petegem, S. (2013). Autonomy in family decision-making among Chinese adolescents: Disentangling the dual meaning of autonomy. Journal of Cross-cultural Psychology. 
Creed, P.A., \& Bartrum, D. (2006). Explanations for deteriorating wellbeing in unemployed people: Specific unemployment theories and beyond. In T. Kieselbach (Ed.), Unemployment and Health: International and Interdisciplinary Perspectives (pp.1-20). Bowen Hills, Qld.: Australian Academic Press.

Creed, P.A., King, V., Hood, M., \& McKenzie, R. (2009). Goal orientation, self-regulation strategies, and job-seeking intensity in unemployed adults. Journal of Applied Psychology, 94, 806-813.

Creed, P., \& Klisch, J. (2005). Future outlook and financial strain: Testing the personal agency and latent deprivation models of unemployment and well-being. Journal of Occupational Health Psychology, 3, 251-260.

Crossley, C. D., \& Highhouse, S. (2005). Relation of job search and choice process with subsequent satisfaction. Journal of Economic Psychology, 26, 255-268.

Deci, E. L. (1975). Intrinsic motivation. New York: Plenum Publishing Co.

Deci, E. L. (1992). On the nature and functions of motivation theories. Psychological Science, 3, 167-171.

Deci, E. L., \& Ryan, R. M. (1985). Intrinsic motivation and self-determination in human behavior. New York: Plenum Publishing Co

Deci, E. L., \& Ryan, R. M. (2000). The 'what' and 'why' of goal pursuits: Human needs and the self-determination of behavior. Psychological Inquiry, 11, 227-268.

Deci, E. L., \& Ryan, R. M. (2012). Motivation, personality, and development within embedded social contexts: An overview of self-determination theory. In R. M. Ryan (Ed.), Oxford handbook of human motivation (pp. 85-107). Oxford, UK: Oxford University Press. 
Deci, E. L., \& Vansteenkiste, M. (2004). Self-determination theory and basic need satisfaction: Understanding human development in positive psychology. Ricerche di Psichologia, 27, $17-34$.

De Witte, H. (1993). Psychological consequences of long-term unemployment: Review of the literature. Psychologica Belgica, 33, 1-35.

De Witte, H., \& Wets, J. (1996). On the heterogeneity of the experience of long-term unemployment among young women. In P. De Goede, P. De Klaver, J. Van Ophem, C. Verhaar, \& A. De Vries (Eds.), Youth: Unemployment, identityand policy (pp. 65-85). Avebury: Aldershot.

Duriez, B., Soenens, B., \&Vansteenkiste, M. (2007). In search of the antecedents of adolescent authoritarianism: The relative contribution of parental goal promotion and parenting style dimensions. European Journal of Personality, 21, 507-527.

Feather, N. T. (1990). The psychological impact of unemployment. New York: Springer-Verlag.

Feather, N. T. (1992). Values, valences, expectations, and actions. Journal of Social Issues, 48, 109-124.

Feather, N. T. \& Davenport, P. R. (1981). Unemployment and depressive affect: A motivational and attributional analysis. Journal of Personality and Social Psychology, 41, 422-436

Fryer, D., \& Payne, R. L. (1986). Being unemployed: A review of the literature on the psychological experience of unemployment. In C. L. Cooper \& I. Robertson (Eds.), International review of industrial and organizational psychology (pp. 235-278). Chichester: Wiley.

Fryer, D. (1986). Employment deprivation and personal agency during unemployment: A critical discussion of Jahoda's explanation of the psychological effects of unemployment. Social Behaviour, 1, 3-23. 
Furnham, A. (1987). Work-related beliefs and human values. Personality and Individual Differences, 8, 627-637.

Gillet, N., Vallerand, R. J., \& Rosnet, E. (2009). Motivational clusters and performance in a reallife setting. Motivation and Emotion, 33, 49-62.

Grolnick, W. S., \& Ryan, R. M. (1989). Parent styles associated with children's self-regulation and competence in school. Journal of Educational Psychology, 81, 143-154.

Gollwitzer, P. M. \& Brandstatter, V. (1990). Implementation intentions and effective goal pursuit. Journal of Personality and Social Psychology, 73, 186-199.

Halvari, H., Vansteenkiste, M., Brorby, S., \& Karlsen, H-P. (2013). Examining antecedents and outcomes of part-time working nurses' motives to search and not-to-search for a full-time position. Journal of Applied Social Psychology, 43, 1608-1623.

Haerens, L., Kirk, D., Cardon, G., De Bourdeaudhuij, I., \& Vansteenkiste, M. (2010). Motivational profiles for secondary school physical education and its relationship to the adoption of a physically active lifestyle among university students. European Physical Education Review, 16, 117-139.

Hayenga, A. O., \& Corpus, J. H. (2010). Profiles of intrinsic and extrinsic motivation: A personcentered approach to motivation and achievement in middle school. Motivation and Emotion, 34, 371-383.

Hodgins, H. S., \& Knee, C. R. (2002). The integrating self and conscious experience. In E. L. Deci \& R. M. Ryan (Eds.). The handbook of self-determination research, (pp. 87-100). Rochester, NY: University of Rochester Press.

Hodgins, H. S., Yacko, H. A., \& Gottlieb, E. (2006). Autonomy and non-defensiveness. Motivation and Emotion, 30, 283-293. 
Hodgins, H. S., Weibust, K. S., Weinstein, N., Shiffman, S., Miller, A., Coombs, G., \& Adair, K. C. (2010). The cost of self-protection: Threat response and performance as a function of autonomous and controlled motivations. Personality and Social Psychology Bulletin, 36, 184-191.

Jahoda, M. (1981). Work, employment, and unemployment: Values, theories, and approaches in social research. American Psychologist, 36, 184-191.

Jahoda, M. (1982). Employment and unemployment: A socio-psychological analysis. Cambridge: Cambridge University Press.

Jang, H., Reeve, J., \& Deci, E. L. (2010). Engaging students in learning activities: It's not autonomy support or structure, but autonomy support and structure. Journal of Educational Psychology, 102, 588-600.

Kanfer, R., Wanberg, C. R., \&Kantrowitz, T. M. (2001). Job search and employment: A personality-motivational analysis and meta-analytic review. Journal of Applied Psychology, 86, 837-855.

Kasser, T., \& Ahuvia, A. C. (2002). Materialistic values and well-being in business students. European Journal of Social Psychology, 32, 137-146.

Kasser, T., \& Ryan, R. M. (1996). Further examining the American dream: Differential correlates of intrinsic and extrinsic goals. Personality and Social Psychology Bulletin, 22, 280-287.

Koen, J., Klehe, U. C., Van Vianen, A. E. M. (2010). Job search strategies and reemployment quality - the impact of career adaptability. Journal of Vocational Behavior, 77, 126-139.

Koen, J., Klehe, U. C., Van Vianen, A. E. M. (in press). Job search and employability after compulsory reemployment courses: The role of choice, usefulness, and motivation. Journal of Occupational and Organisational Psychology. 
Koestner, R., \& Losier, G. F. (2002). Distinguishing three ways of being highly motivated: A closer look at introjection, identification, and intrinsic motivation. In E. L. Deci \& R. M. Ryan (Eds.), Handbook of self-determination research (pp. 101-121). Rochester, NY: University of Rochester Press.

Koestner, R., Lekes, N., Powers, T. A., \& Chicoine, E. (2002). Attaining personal goals: Selfconcordance plus implementation intentions equals success. Journal of Personality and Social Psychology, 83, 231-244.

Kristof-Brown, A., Zimmerman, R., \& Johnson, E. (2005). Consequences of individuals' fit at work: A meta-analysis of person-job, person-organization, person-group, and personsupervisor fit. Personnel Psychology, 58, 285-342.

Kroger, J. \& Marcia, J. E. (2011). The identity statuses: Origins, meanings, and interpretations. In S. J. Schwartz, K. Luyckx, \& V. L. Vignoles (Eds.), Handbook of Identity Theory and Research, (pp. 31-54). New York: Springer.

La Guardia, J. G. (2009). Developing who I am: A Self-Determination Theory approach to the establishment of healthy identities. Educational Psychologist, 44, 90-104.

Marcia, J. E. (1966). Development and validation of ego identity status. Journal of Personality and Social Psychology, 3, 551-558.

Markland, D., Ryan, R. M., Tobin, V. J., Rollnick, S. (2005). Motivational interviewing and selfdetermination theory. Journal of Social and Clinical Psychology, 24, 811-831.

McKee-Ryan, F. M., Song, Z. L., Wanberg, C. R., \& Kinicki, A. J. (2005). Psychological and physical well-being during unemployment: A meta-analytic study. Journal of Applied Psychology, 90, 53-76. 
Meyer, B., Enström, M. K., Harstveit, M., Bowles, D. P., \& Beevers, C. G. (2007). Happiness and despair on the catwalk: Need satisfaction, well-being, and personality adjustment among fashion models. Journal of Positive Psychology, 2, 2-17.

Miller, W. R., \& Baca, L. M. (1983). Two-year follow-up of bibliotherapy and therapist-directed controlled drinking training for problem drinkers. Behavior Therapy, 14, 441-448.

Miller, J. G., Das, R., \& Chakravarthy, S. (2011). Culture and the role of choice in agency. Journal of Personality and Social Psychology, 101, 46-61.

Miller, W.R., Taylor, C.A., \& West, J.C. (1980). Focused versus broad spectrum behavior therapy for problem drinkers. Journal of Consulting and Clinical Psychology, 48, 590601.

Miller, W. R., \& Rollnick, S. (2002). Motivational interviewing. New York: Guilford Press.

Muller, J. J., Creed, P. A., Waters, L. E., \& Machin, M. A. (2005). The development and preliminary testing of a scale to measure the latent and manifest benefits of employment. European Journal of Psychological Assessment, 21, 191-198

Paul, K. L., \& Batinic, B. (2010). The need for work: Jahoda's latent functions of employment in a representative sample of the German population. Journal of Organizational Behavior, 31, 45-64.

Paul, I., \& Moser, K. (2009). Unemployment impairs mental health: Meta-analyses. Journal of Vocational Behavior, 74, 264-282.

Promislo, M. D., Deckop, J. R., Giacalone, R. A., \& Jurkiewicz, C. L. (2010). Valuing money more than people: The effects of materialism on work-family conflict. Journal of Occupational and Organizational Psychology, 83, 935-953.

Roth, G., Assor, A., Niemiec, C. P., Ryan, R. M., \& Deci, E. L. (2009). The emotional and academic consequences of parental conditional regard: Comparing conditional positive 
regard, conditional negative regard, and autonomy support as parenting practices. Developmental Psychology, 45, 1119-1142.

Reeve, J. (2006). Teachers as facilitators: What autonomy-supportive teachers do and why their students benefit. Elementary School Journal, 106, 225-236.

Reeve, J., Jang, H., Carrell, D., Jeon, S., \& Barch, J. (2004). Enhancing students' engagement by increasing teachers' autonomy support. Motivation and Emotion, 28, 147-169.

Reilly, P.A. (1998). Balancing flexibility: Meeting the interests of employers and employee. European Journal of Work and Organizational Psychology, 7, 7-22.

Ryan, R. M. (1995). Psychological needs and the facilitation of integrative processes. Journal of Personality, 63, 397-427.

Ryan, R. M., Bernstein, J. H., \& Brown, K. W. (2010). Weekends, work, and well-being: Psychological need satisfactions and day of the week effects on mood, vitality, and physical symptoms. Journal of Social and Clinical Psychology, 29, 95-122.

Ryan, R. M., \& Deci, E. L. (1999). Approaching and avoiding self-determination: Comparing cybernetic and organismic paradigms of motivation. In C. Carver \& M. Scheier (Eds.), Perspectives on behavioral self-regulation: Advances in social cognition (pp. 193-215). Mahwah, NJ: Lawrence Erlbaum Associates Publishers.

Ryan, R. M., \& Deci, E. L. (2000a). Self-determination theory and the facilitation of intrinsic motivation, social development, and well-being. American Psychologist, 55, 68-78.

Ryan, R. M., \& Deci, E. L. (2000b). The darker and brighter sides of human existence: Basic psychological needs as a unifying concept. Psychological Inquiry, 11, 319-338

Ryan, R. M., Lynch, M. F., Vansteenkiste, M., \& Deci, E. L. (2011). Motivation and autonomy in counseling, psychotherapy, and behavior change: A look at theory and practice. The Counseling Psychologist, 39, 193-260. 
Ryan, R. M., Sheldon, K. M., Kasser, T., \& Deci, E. L. (1996). All goals are not created equal: An organismic perspective on the nature of goals and their regulation. In P. M. Gollwitzer\& J. A. Bargh (Eds.), The psychology of action: Linking cognition and motivation to behavior (pp. 7-26). New York: Guilford Press.

Sagiv, L., \& Schwartz, S. H. (2000). Value priorities and subjective well-being: Direct relations and congruity effects. European Journal of Social Psychology, 30, 177-198.

Schmuck, P., Kasser, T., \& Ryan, R. M. (2000). Intrinsic and extrinsic goals: Their structure and relationship to well-being in German and U.S. college students. Social Indicators Research, 50, 225-241.

Sebire, S., Standage, M., \& Vansteenkiste, M. (2009). Examining intrinsic versus extrinsic exercise goals: Cognitive, affective, and behavioral Outcomes. Journal of Sport \& Exercise Psychology, 31, 189-210.

Senécal, C., \& Guay, F. (2000). Procrastination in job seeking: an analysis of motivational processes and feelings of hopelessness. In J. R. Ferrari, \& T. A. Pychyl (Eds.), Procrastination: Current Issues and New Directions (Special Issue). Journal of Social Behavior and Personality, 15(5), 267-282.

Sheldon, K. M., Cheng, C., \& Hilpert, J. (2011). Understanding Well-Being and Optimal Functioning: Applying the Multilevel Personality in Context (MPIC) Model. Psychological Inquiry, 22, 1-16.

Sheldon, K. M., Sheldon, M. S., \& Osbaldiston, R. (2000). Prosocial values and group assortation within an N-person prisoner's dilemma game. Human Nature, 11, 387-404.

Sierens, E., Vansteenkiste, M., Goossens, L., Soenens, B., \& Dochy, F. (2009). The synergistic effect of perceived teacher autonomy-support and structure in the prediction of selfregulated learning. British Journal of Educational Psychology, 79, 57-68. 
Soenens, B., \& Vansteenkiste, M. (2005). Antecedents and outcomes of self-determination in 3 life domains: The role of parents' and teachers' autonomy support. Journal of Youth and Adolescence, 34, 589-604.

Soenens, B. \& Vansteenkiste, M. (2011). When is identity congruent with the self? A selfdetermination theory perspective. In S.J. Schwartz, K. Luyckx\& V.L. Vignoles (Eds.) Handbook of Identity Theory and Research (pp.381-402).

Van den Broeck, A., Lens, W., De Witte, H., \& Van Coillie, H. (2013). Unraveling the importance of the quantity and the quality of workers' motivation for well-being: A person-centered perspective. Journal of Vocational Behavior, 82, 69-78.

Van den Broeck, A., Van Ruysseveldt, J., \& De Witte, H. (in press). Does an intrinsic work value orientation strengthen the impact of job resources? A perspective from the Job DemandsResources Model. European Journal of Work and Organizational Psychology.

Van den Broeck, A., Vansteenkiste, M., De Witte, H., Soenens, B., \& Lens, W. (2010). Capturing autonomy, competence, and relatedness at work: Construction and initial validation of the Work-related Basic Need Satisfaction scale. Journal of Occupation and Organizational Psychology, 83, 981-1002.

Van den Broeck, A., Vansteenkiste, M., Lens, W., \& De Witte, H. (2010). Unemployed individuals' work values and flexibility: A comparison of expectancy-value theory and self-determination theory. Applied Psychology: An International Review, 59,296-317.

Vandoorne, J., De Witte, H., \& Hooge, J. (2000), Werk in zicht: houding ten aanzien van arbeid en toekomstperspectief op de arbeidsmarkt [Work in sight: attitude toward work and future perspective on the labour market], in H. De Witte, J. Hooge \& L. Walgrave (red.), Jongeren in Vlaanderen: gemeten en geteld. 12- tot 18- jarigen over hun leefwereld en toekomst. (pp. 185-208). Leuven: Universitaire Pers Leuven. 
Van Hooft, E. A. J., Born, M, Taris, T. W., van der Flier, H., \& Blonk, R. W. B. (2005). Bridging the gap between intentions and behavior: Implementation intentions, action control, and procrastination. Journal of Vocational Behavior, 66, 238-256.

Van Hooft, E. A. J., Wanberg, C. R., \& Van Hoye, G. (2013). Moving beyond job search quantity: Towards a conceptualization and self-regulatory framework of job search quality. Organizational Psychology Review, 3, 3-40.

Van Hoye, G. (this volume). Job search behavior as a multidimensional construct: An overview of different job search behaviors and sources.

Vansteenkiste, M. (2010, May). Motivational profiles from a self-determination theory perspective. Paper presented at the 4th Conference on Self-Determination Theory (SDT), Ghent, Belgium.

Vansteenkiste, M., De Witte, H., \& Lens, W. (2006). Explaining the negative relationship between length of unemployment and the willingness to undertake a job training: A selfdetermination perspective. In T. Kieselback \& T. Winefield (Eds.), Unemployment and Health, International and Interdisciplinary Perspectives (pp. 199-217). Bowen Hills: Australian Academic Press.

Vansteenkiste, M., Duriez, B., Simons, J., \& Soenens, B. (2006). Materialistic values and wellbeing among business students: Further evidence for their detrimental effect. Journal of Applied Social Psychology, 36, 2892-2908.

Vansteenkiste, M., Lens, W., De Witte, H., \& Feather, N. T. (2005). Understanding unemployed people's job search behaviour, unemployment experience and wellbeing: A comparison of expectancy-value theory and self-determination theory. British Journal of Social Psychology, 44, 269-287. 
Vansteenkiste, M., Lens, W., Soenens, B., \& Luyckx, K. (2006). Autonomy and relatedness among Chinese sojourners and applicants: Conflictual or independent predictors of wellbeing and adjustment? Motivation and Emotion, 30, 273-282.

Vansteenkiste, M., Lens, W., De Witte, S., De Witte, H., \&Deci, E. L. (2004). The 'why' and 'why not' of job search behaviour: Their relation to searching, unemployment experience, and well-being. European Journal of Social Psychology, 34(3), 345-363.

Vansteenkiste, M., Neyrinck, B., Niemiec, C. P., Soenens, B., De Witte, H., \& Van Den Broeck, A. (2007). On the relations among work value orientations, psychological need satisfaction, and job outcomes: A self-determination theory approach. Journal of Occupational and Organizational Psychology, 80, 251-277.

Vansteenkiste, M., Niemiec, C., \& Soenens, B. (2010). The development of the five mini-theories of self-determination theory: An historical overview, emerging trends, and future directions. In T. Urdan \& S. Karabenick (Eds.), Advances in Motivation and Achievement (Vol. 16). Bingley, UK: Emerald Publishing.

Vansteenkiste, M., \& Ryan, R. M. (2013). On psychological growth and vulnerability: Basic psychological need satisfaction and need frustration as an unifying principle. Journal of Psychotherapy Integration.

Vansteenkiste, M., Sierens, E., Soenens, B., Luyckx, K., \& Lens, W. (2009). Motivational profiles from a self-determination theory perspective: The quality of motivation matters. Journal of Educational Psychology, 101, 671-688.

Vansteenkiste, M., Simons, J., Lens, W., Soenens, B., \& Matos, L. (2005). Examining the motivational impact of intrinsic versus extrinsic goal framing and autonomy-supportive versus internally controlling communication style on early adolescents' academic achievement. Child Development, 76, 483-501. 
Vansteenkiste, M., Simons, J., Lens, W., Sheldon, K. M., \&Deci, E. L. (2004). Motivating learning, performance, and persistence: The synergistic effects of intrinsic goal contents and autonomy-supportive contexts. Journal of Personality and Social Psychology, 87, 246-260.

Vansteenkiste, M., Soenens, B., \& Duriez, B. (2008). Presenting a positive alternative to materialistic strivings and the thin-ideal: Understanding the effects of extrinsic relative to intrinsic goal pursuits. In Lopez, S. J. (Ed.) Positive psychology: Exploring the best in people (Vol. 4, pp. 57-86). Westport, CT: Greenwood Publishing Company.

Vansteenkiste, M., Soenens, B., Van Petegem, S., \& Duriez, B. (2013). The relation between degree and style of prohibition and adolescent internalisation and oppositional defiance. Developmental Psychology.

Vansteenkiste, M., Williams, G. C., \& Resnicow, K. (2012). Toward systematic integration between Self-Determination Theory and motivational interviewing as examples of topdown and bottom-up intervention development: Autonomy or volition as a fundamental theoretical principle. International Journal of Behavioral Nutrition and Physical Activity, $9: 23$.

Underlid, K. (1996). Activity during unemployment and mental health. Scandinavian Journal of Psychology, 37, 269-281.

Verstuyf, J., Vansteenkiste, M., \& Soenens, B. (in press). Eating regulation and bulimic symptoms: The differential correlates of health-focused and appearance-focused eating regulation. Body Image: An International Journal of Research.

Vinokur, A. D., \& Schul, Y. (2002). The web of coping resources and pathways to reemployment following a job loss. Journal of Occupational Health Psychology, 5, 32-47. 
Wanberg, C. (in press). The individual experience of unemployment. Annual Review of Psychology, 63, 369-396.

Wanberg, C., Hough, L. M., \& Song, z. (2002). Predictive validity of a multidisciplinary model of reemployment success. Journal of Applied Psychology, 87, 1100-1120.

Wanberg, C. R., Zhu, J., Kanfer, R., \& Zhang, Z. (2012). After the pink slip: Applying dynamic motivation frameworks to the job search experience. Academy of Management Journal, 55, 261-284.

Wanberg, C. Zu, J., \& Van Hooft, A. J. (2010). The job search grind: perceived progress, selfreactions, and self-regulation of search effort. Academy of Management Journal, 53, 788807.

Warr, P. (1987). Work, Unemployment, and Mental Health, Clarendon Press, Oxford.

Weiner, B.(1985). An attributional theory of achievement motivation and emotion. Psychological Review, 92, 548-573.

Wilson, P. M., Rogers, W. T., Rodgers, W. M., \& Wild, T. C. (2006). The psychological need satisfaction in exercise scale. Journal of Sport and Exercise Psychology, 28, 231-251. 
Figure 1

Schematic Representation of the Types of Motivation and Regulation within Self-Determination Theory (adapted from Ryan \& Deci, 2000a)

Lack of

Intention

Intentional Behavior

\begin{tabular}{|c|c|c|c|c|c|}
\hline Amotivation & \multicolumn{4}{|c|}{ Extrinsic Motivation } & Intrinsic \\
\hline Nonregulation & $\begin{array}{c}\text { External } \\
\text { Regulation }\end{array}$ & $\begin{array}{l}\text { Introjected } \\
\text { Regulation }\end{array}$ & $\begin{array}{l}\text { Identified } \\
\text { Regulation }\end{array}$ & $\begin{array}{l}\text { Integrated } \\
\text { Regulation }\end{array}$ & $\begin{array}{c}\text { Intrinsic } \\
\text { Regulation }\end{array}$ \\
\hline $\begin{array}{c}\text { Lack of } \\
\text { expectations } \\
\text { Lack of } \\
\text { valuation }\end{array}$ & $\begin{array}{c}\text { External } \\
\text { expectations, } \\
\text { Threatening } \\
\text { sanctions } \\
\text { Controlling } \\
\text { rewards }\end{array}$ & $\begin{array}{c}\text { Guilt, } \\
\text { Shame, } \\
\text { Anxiety } \\
\text { Contingent } \\
\text { self-worth }\end{array}$ & $\begin{array}{l}\text { Conscious } \\
\text { valuation } \\
\text { Personal } \\
\text { meaning }\end{array}$ & $\begin{array}{c}\text { Fit with other } \\
\text { values } \\
\text { Harmony, } \\
\text { coherence }\end{array}$ & $\begin{array}{c}\text { Interest, } \\
\text { enjoyment, } \\
\text { pleasure, } \\
\text { Curiosity }\end{array}$ \\
\hline $\begin{array}{c}\text { Lack of } \\
\text { Motivation }\end{array}$ & $\begin{array}{r}\text { Controlled } \\
\text { Musti }\end{array}$ & $\begin{array}{l}\text { tivation } \\
\text { on }\end{array}$ & & Autonomous Motivation & \\
\hline $\begin{array}{c}\text { Least } \\
\text { Self- } \\
\text { Determined }\end{array}$ & & & & & $\begin{array}{c}\text { Most } \\
\text { Self-Determined }\end{array}$ \\
\hline
\end{tabular}

